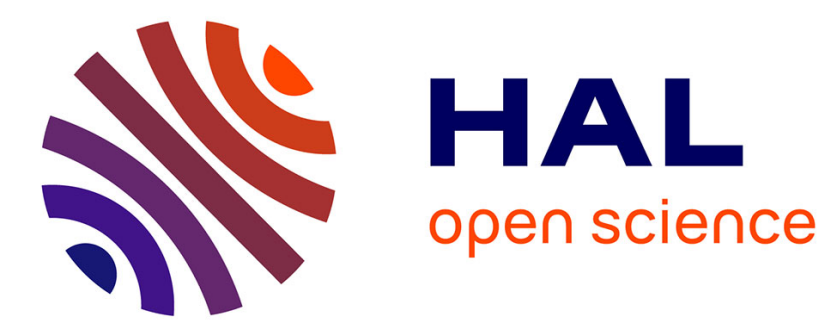

\title{
On material flow in Friction Stir Welded Al alloys
}

\author{
Amèvi Tongne, Christophe Desrayaud, M Jahazi, Eric Feulvarch
}

\section{To cite this version:}

Amèvi Tongne, Christophe Desrayaud, M Jahazi, Eric Feulvarch. On material flow in Friction Stir Welded Al alloys. Journal of Materials Processing Technology, 2017, 239, pp.284-296. 10.1016/j.jmatprotec.2016.08.030 . emse-01525251

\section{HAL Id: emse-01525251 \\ https://hal-emse.ccsd.cnrs.fr/emse-01525251}

Submitted on 13 Sep 2021

HAL is a multi-disciplinary open access archive for the deposit and dissemination of scientific research documents, whether they are published or not. The documents may come from teaching and research institutions in France or abroad, or from public or private research centers.
L'archive ouverte pluridisciplinaire HAL, est destinée au dépôt et à la diffusion de documents scientifiques de niveau recherche, publiés ou non, émanant des établissements d'enseignement et de recherche français ou étrangers, des laboratoires publics ou privés. 


\title{
On material flow in Friction Stir Welded Al alloys
}

\author{
A. Tongne ${ }^{\mathrm{a}}$, C. Desrayaud ${ }^{\mathrm{b}}$, M. Jahazi $^{\mathrm{c}}$, E. Feulvarch $^{\mathrm{a}, *}$ \\ a Univ. Lyon, ENISE, LTDS, UMR 5513 CNRS, 58 rue Jean Parot, F-42023 Saint-Etienne cedex 2, France \\ ${ }^{\mathrm{b}}$ Ecole des Mines de Saint-Etienne, LGF UMR 5307 CNRS, 158 Cours Fauriel, F-42023 Saint-Etienne, France \\ ${ }^{\mathrm{c}}$ Ecole de Technologie Superieure, 1100 Rue Notre-Dame Ouest, Montreal, QC H3C 1K3, Canada
}

\begin{abstract}
AA6082-T6 joints were produced using a trigonal shape pin. The influence of Friction Stir Welding (FSW) process parameters on the formation of banded structures was predicted using numerical modeling and then experimentally validated by optical and electron microscopy. Special attention was paid to the for-mation and evolution of banded structures observed in the plane of the welded sheets. A finite element (FE) analysis based on the Coupled Eulerian-Lagrangian formulation was developed to predict and quan-tify the influence of FSW process parameters on the formation and extent of the banded structures. The combination of the experimental and numerical analyses showed that the formation of the banded struc-tures is mainly related to the geometry of the pin whereas the friction conditions have a much smaller effect.
\end{abstract}

\section{Introduction}

Friction Stir Welding (FSW) is a solid state joining process in which a rotational tool moves along the interface of the parts to be welded. Joining is performed by stirring the interface, which is facilitated by heating due to plastic dissipation as well as friction between tool and workpieces. Friction stir welds have superior mechanical strengths when compared to conventional welding processes. MIG, TIG and FSW welds of aluminum alloy 5086-H32 have been studied by Taban and Kaluc (2007). The comparison shows that FSW welds are the strongest ones both for bending and tensile tests. Fatigue tests carried out by Ericsson and Sandström (2003) on welds made of aluminum alloy 6082 showed that the fatigue strength of FSW welds is higher than that of MIG and TIG welds. For FSW welds, the material forming the joint undergoes different thermomechanical histories depending on its location in the joint. This gradient in thermomechanical history results in various microstructural features and plays major role in determining the mechanical strength of the joint. The microstructure of the joint exhibits a number of characteristic features such as:

- Kissing bonds which correspond to a specific type of solid-state bonding defect where the two materials to be welded are in contact with little or no metallic bond as reported by Xu and Deng

\footnotetext{
* Corresponding author.

E-mail address: eric.feulvarch@enise.fr (E. Feulvarch).
}

(2008). Crack growth along the kissing bonds have been observed by Jene et al. (2006) on friction stir welds made of aluminum alloy 5454.

- Banded structures consisting of alternating clear and dark bands. This phenomenon leads to the formation of onion rings which can be observed on the cross section of the weld joint, as studied by Krishnan (2002), using semicylinder clay model. The periodical material deposition has also been observed with a high speed camera by Gratecap et al. (2011) during FSW of plasticine.

- Void defects such as porosities or tunnel defects as observed by Kumar and Kailas (2008) which correspond to the lack of material flow in the retreating side of the joint.

Therefore, understanding material flow during FSW is crucial for controlling the weld quality, especially for complex tool geometries. In literature, a number of techniques have been used to study material flow during FSW. Steel balls have been used by Colligan (1999) as markers in the weld seam. Liechty and Webb (2007) carried out FSW welds by using plasticine with dissimilar color in order to observe the material stirring during the process. Even though the information provided by these techniques is valuable, it is not accurate enough to explain specific phenomena observed in metallic FSW welds such as the contrast difference between the bands. For FSW welds made of aluminum alloys, material flow during the welding stage can be reliably described by analyzing the elements in the weld microstructure. This approach was used by few authors in the literature. The formation mechanism of kissing bonds was investigated by Xu and Deng (2008) by inserting a thin 
sheet $(0.1 \mathrm{~mm})$ of pure aluminum at the interface of the AA6061-T6 plates to be welded, in order to increase the visibility of the resulting kissing bonds. In their study, the evolution of the kissing bonds as well as banded structure shapes as a function of the welding speeds was investigated. They reported that kissing bonds are often dragged into the banded region. This indicates that banded structures are highly related to the mixing of materials across the width of the weld. The formation mechanism of void defects was studied extensively by Kumar and Kailas (2008). The authors showed that void defects decrease when the welding force increases. Cui et al. (2008) used the stop action technique to study the material layer deposition mechanism. The technique is experimental and consists in leaving the tool inside the weld and observes the joint using optical and/or electron microscopy. However, an "a posteriori" description of the material flow during FSW welding must be checked through numerical investigations such as those carried out by Xu and Deng (2008) to predict banded structures produced by a cylindrical pin.

The main approach used for simulation of the FSW process is a solid mechanics type including large strains and strain rates. Several finite element formulations have been applied to simulate material flow during FSW. With a Lagrangian formalism, a step by step analysis needs to be performed to follow the movement of the tool and especially, the rotation of the pin. If such simulations seem to be very useful to study the process step corresponding to the penetration of the pin into the material, it is very time consuming to get the material flow during steady state welding conditions. In addition, as the mesh follows the material flow, the large distortions lead to unacceptable finite element distortions. The local modeling of mechanical effects requires refined meshes along the trajectory of the stirring zone which leads to significant size of the numerical problems that need to be solved. This can be avoided by means of refining discretization only in the vicinity of the welding zone using a re-meshing procedure. However, this approach increases the computational cost. The Arbitrary Lagrangian-Eulerian approach (ALE) can be used to obtain realistic computation times as suggested by Assidi et al. (2010) and Timesli et al. (2012). It consists in introducing a relative movement between the mesh and the welded material in order to decrease mesh distortions. The main drawback of this approach remains in the choice of the relative movement. Despite the complexity of such an approach, the formation of void defects has been well predicted by the model developed by Schmidt and Hattel (2005). An alternative approach consists in using meshless techniques such as the Smoothed-Particle Hydrodynamics (SPH) applied by Lorrain et al. (2009) and Tartakovsky et al. (2006), or the Moving Particle Semiimplicit (MPS) method used by Yoshikawa et al. (2012). However, as transient simulations must be performed, these approaches are complicated to implement and very time consuming as shown by Assidi et al. (2010) and Schmidt and Hattel (2005).

Like most welding processes, the FSW process involves a small size welding zone compared to that of the studied structure. It is very often assumed that a periodic state is reached when the welded structure displays a translational geometry over a long distance. Therefore, the material flow during the welding phase of the process can be calculated using an analysis with a reference frame linked to the welding velocity in an Eulerian formalism as used by Colegrove and Shercliff (2004), Jacquin et al. (2011) and Bastier et al. (2006), thus significantly reducing the computational efforts by avoiding the transient analysis. For non-axisymmetric tools, the periodic phase of the process can be simulated within an Eulerian formalism coupled with a simple moving mesh technique as proposed by Feulvarch et al. (2012) and latter applied by Dialami et al. (2013). The mesh is composed of two parts: a first one which is fixed around the stirring zone and a second one which includes the material under the tool and moves with a rotational solid motion

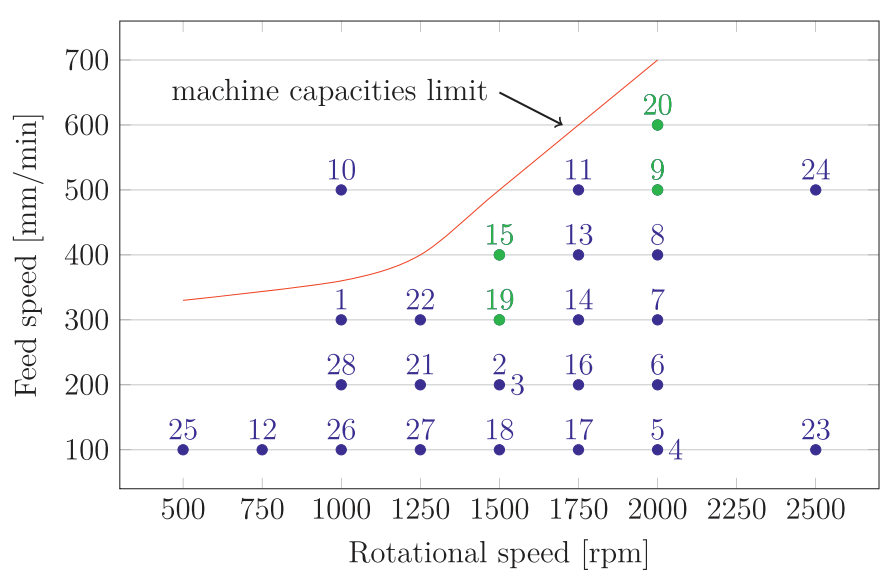

Fig. 1. Welding configurations (defective welds are indicated in blue). (For interpretation of the references to color in this figure legend, the reader is referred to the web version of the article.)

corresponding to the tool rotational velocity. Using the above approach, the mesh distortion problem is solved. The Eulerian formalism has the advantage of requiring much lower computation time as underlined by Tutum and Hattel (2011). With the mixture theory developed by Benson (1997), an enhanced boundary method can also be used to model the tool rotation. The geometrical volume of the pin is considered as a void inserted at each time step in the Eulerian media, where the welded material can flow. The contact mixture theory provided by Benson (1997) automatically computes and tracks the interface between the Lagrangian tool and the Eulerian welded material. Therefore, it is possible to simulate complex tool geometries as there is no requirement for fitting Eulerian mesh boundaries to the tool geometry. This approach is referred to as the Coupled Eulerian-Lagrangian (CEL). Recently, it has been used by Al-Badour et al. (2013) to predict void defects and flashes in FSW welds. Malik et al. (2014) have investigated the effect of various tool pin profiles using this approach. However, the CEL method has never been used to study the formation and evolution of the banded structures in FSW joints.

In the present paper material flow during FSW of $6 \mathrm{~mm}$ thick AA6082-T6 sheets using a trigonal shape pin is investigated by experimentation and modeling. In the first part, the influence of welding speed on the characteristics of the banded structure in the plane of the welded sheets is investigated. In the second part of the paper, a 2D numerical analysis based on the CEL formulation is used to analyze and predict the formation of banded structures and kissing bonds in the investigated material.

\section{Experimental analysis}

The details of the FSW experiments have been already provided in a previous publication of Tongne et al. (2015). The plates are made of aluminum alloy 6082-T6 with a thickness equal to $6 \mathrm{~mm}$. Welding is carried out by means of a carbide trigonal tool. The height and the mean diameter of the pin are equal to $5 \mathrm{~mm}$ and $5.5 \mathrm{~mm}$, respectively and the tool shoulder diameter equals $12 \mathrm{~mm}$. The tilt angle is $1^{\circ}$. The total weld length is about $25 \mathrm{~mm}$ to be sure of achieving the stationary state as shown by Giraud et al. (2016) for the same welding setup. Fig. 1 summarizes the FSW processing map where the sound and defective welds are identified as a function of tool rotational speed and welding velocity. The red line denotes the welding limit of the testing machine according to the vibrations and forces which occur during the welding experiments. 


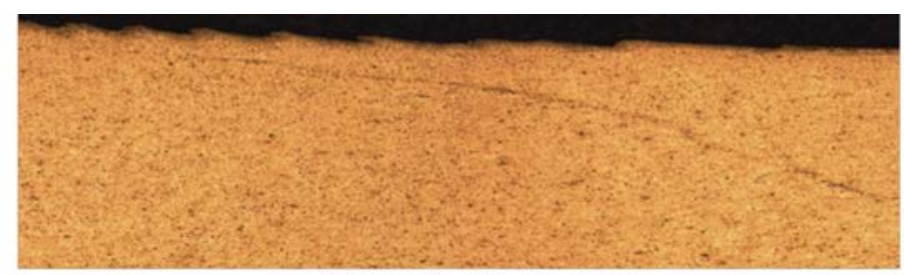

A- Stretched kissing bond
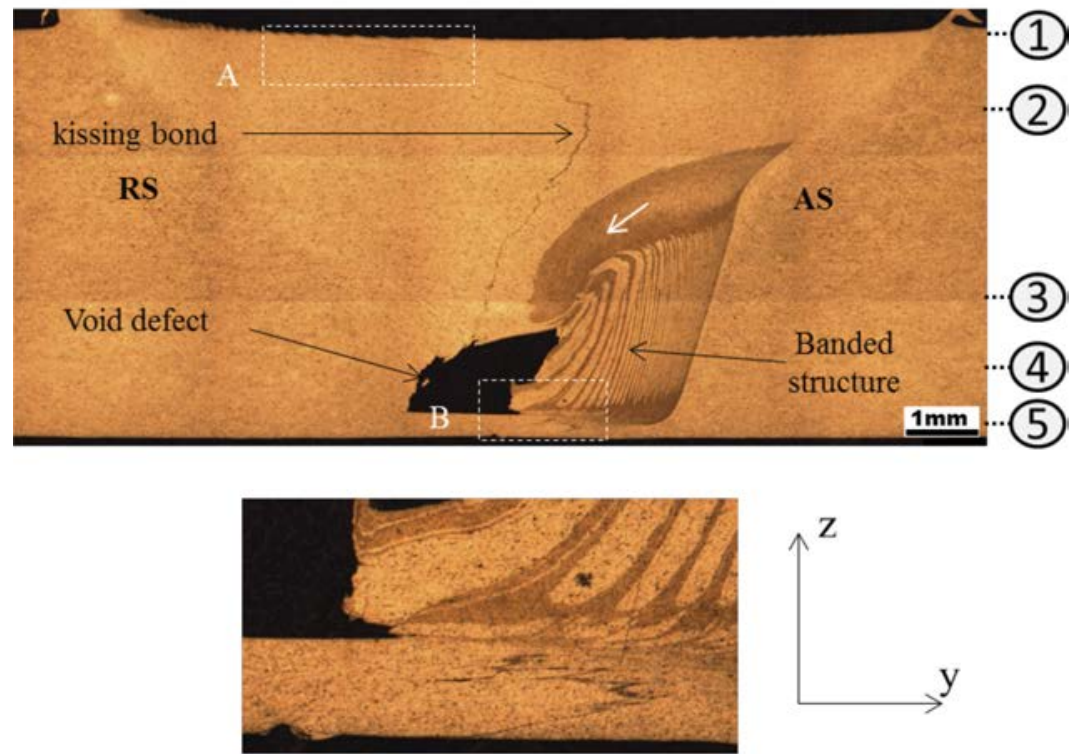

B- Kissing bond at the root of the weld

Fig. 2. Cross-section of a welding sample presenting its features at the center of the weld joint (weld no. $21: 1250 \mathrm{rpm}-200 \mathrm{~mm} / \mathrm{min}$ ).

\subsection{Material flow}

The material flow around the FSW tool can be analyzed by observing the weld microstructure. Krishnan (2002) and Gratecap et al. (2011) have reported that the formation of the banded structure in the weld microstructure is due to periodical deposition of material layers. Xu and Deng (2008) have shown that kissing bonds in FSW can appear in the banded region at the interface between the parts to be welded.

\subsubsection{Void defect}

Fig. 2 shows a typical void defect. As the tool is moving, a continuous longitudinal tunnel following the weld line develops at the back of the welding tool. This phenomenon is due to insufficient driving of the material by the tool. For all defective welds, the void defects are located at the bottom of the weld (see Fig. 2) between the banded structure on the advancing side and the rest of the material located on the retreating side. On the top of the advancing side, the material forming the weld does not exhibit a banded structure, or a void defect. Moreover, a white arrow in Fig. 2 shows material flow going from the top of the advancing side to the void at the bottom. This material flow bends down the head of the banded structure. Actually, the flow of material driven by the rotation of the tool (fluid circulation) is higher on top because of the action of the shoulder. Therefore, from an experimental point of view, the mechanical stirring should be studied accurately to prevent void defects or to control their locations according to the welding velocity as reported by Rajakumar et al. (2011).

\subsubsection{Material interface}

The material interface can be easily observed on experimental samples. In Fig. 2, the material interface starts from the retreating

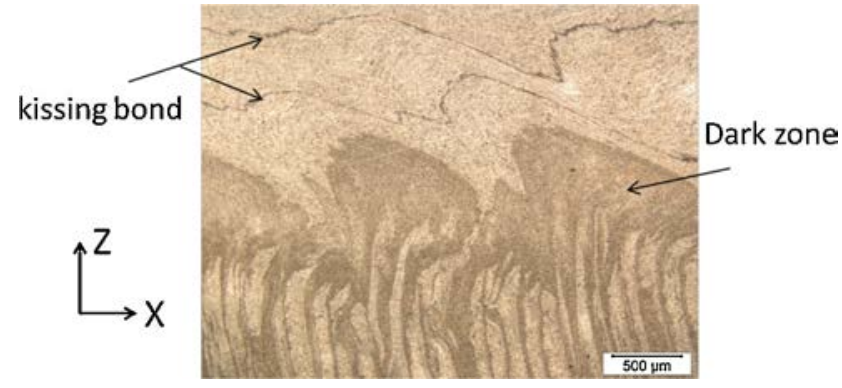

Fig. 3. Material interface in longitudinal section at the center of the weld joint (weld no. 20: $2000 \mathrm{rpm}-600 \mathrm{~mm} / \mathrm{min}$ ).

side at location 1 indicating that fluid circulation is less efficient close to the shoulder. Indeed, the material located on the retreating side is not driven to the advancing side. At position 2, the material interface is located on the advancing side. This means that the fluid circulation at this position is higher than close to the shoulder because the material located on the retreating side is significantly dragged to the advancing side. As mentioned by Kumar and Kailas (2008), this higher fluid circulation induces a three-dimensional material flow which results in the vertical motion. The gradual movement of the material interface from position 1 to position 2 is indicative of the velocity gradient and the corresponding progressive deformation conditions. At position 3 , the material interface is approximately located at the center of the weld joint. It is stretched by the vertical extrusion which bends down the top of the banded structure and produces a dark zone indicated by the white arrow. In Fig. 3, the optical microscopy of the longitudinal section shows that the material interface follows the boundary of the dark zone. 

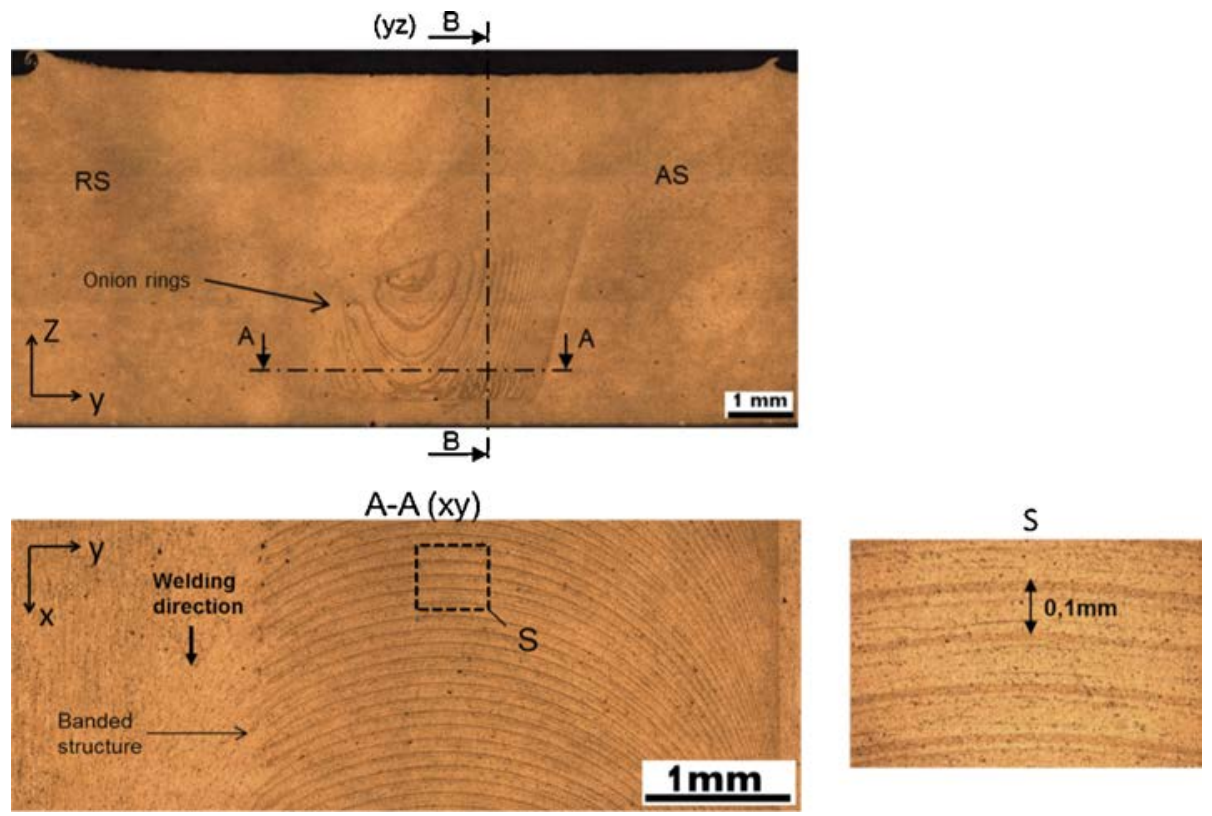

Fig. 4. Banded structure in the weld sections at the center of the weld joint (weld no. 20: $2000 \mathrm{rpm}-600 \mathrm{~mm} / \mathrm{min}$ ).

The material interface therein is double because the plane of observation is crossing a curved interface.

In Fig. 2, a void defect and the banded structure can be identified at position 4 . In the next section, the imbrication of the material interface into the banded structure will be discussed. On the bottom of the stirring zone corresponding to position 5 , the shape of the material interface exhibits a high "zigzag" type frequency, as shown in Fig. 2B. This shows that the FSW process affects the zone under the tool. Actually, this mechanism is essential to avoid root defects: the material must entirely fill the zone under the pin during the welding stage. The material interface is also called a lazy " $\mathrm{S}$ " or a zigzag line as observed by Gibson et al. (2014) and Zhou et al. (2006) or a tip border-shape for dissimilar materials as noticed by Robe et al. (2015).

\subsubsection{Banded structure}

A banded structure which extends from the advancing side toward the retreating side was observed in all welded specimens. Fig. 4 shows the banded structure through different observation planes for a sample welded with $2000 \mathrm{rpm}$ rotational speed and $600 \mathrm{~mm} / \mathrm{min}$ welding speed. On the cross section $(y z)$, microstructural bands are similar to concentric circles and are called "onion rings". As observed in Fig. 4S, the distance between bands is about $0.1 \mathrm{~mm}$, which corresponds to the third of the trigone tool advance per rotation. The above correlation between the tool geometry and the interval between the bands is in agreement with those reported by Gratecap et al. (2011) who used a tool with an axisymmetric geometry and tools without shoulder.

Microhardness analysis on the dark bands, the clear bands and the base material indicate 60,79 and $64 \mathrm{HV}$, respectively. This difference in hardness has also been observed during Differential Interference Contrast (DIC) microscopy observations (see Fig. 5). This type of analysis allows studying the topography of the sample surface. One can note that the dark bands are more eroded by polishing than the other microstructure zones which is an indirect evidence of their lower hardness.

Even if the difference in microhardness between dark and clear bands is confirmed, there is still not any satisfactory explanation of the link between the mechanical properties and the contrast difference. The microhardness of aluminum alloys 6000 series is highly related to the precipitation state which is itself complex to evaluate. However, the presence of the kissing bond in the banded structure characterizes the layer-by-layer deposit of the material at the back of the tool. The material coming from the advancing side closest to the tool is strongly deformed, as has been observed by Prangnell and Heason (2005). Using a "stop action" experiment, Chen and Cui (2008) observed that for a threaded tool, the microstructure is made of a succession of thin and thick layers. Furthermore, at least for our welding experiments, the banded structure does not cover the entire weld width. As shown in Fig. 6(a), two zones can be distinguished on section $A-A$ (see Fig. 4): a No Banded Structure Zone (NBSZ) and a Banded Structure Zone (BSZ). As this section corresponds to the bottom of the weld far from the vertical motion which bends down the banded structure head (see Fig. 4), the material on section $A-A$ originates only from the material deposited by the rotation of the pin as reported by Tongne et al. (2015).

In Fig. 6(b), a banded structure in the two zones and a void defect at the start of the weld joint are observable. The presence of the void reflects the fact that the two banded structures present through the width of the weld do not have the same origin. The material in the BSZ is deposited layer after layer whereas the material in the NBSZ remains attached to the rest of the material to be welded. In the NBSZ, the material is driven into the path of the tool during its forward movement. This phenomenon is similar to the one observed in cutting processes: when the tool passes close to the non-deformed material on the retreating side, the pin removes a layer of material in its rotation by the so-called "plowing" effect. This phenomenon is at the origin of burs. The boundary with the non-deformed base material on the retreating side is less prominent than the one observed on the advancing side for all welding experiments.

Indeed, the material which will form the banded structure has to be deposited when reaching the advancing side. This corresponds to an alternation of more or less sheared material layers. In fact, during the deposition of the material behind the tool, it is released into the space located between the tip of the tool and the previously deposited layer (see Fig. 7). The material released in the vicinity of the tip of the tool is sheared due to its rotational movement. Thus, the material that is away from the tip is retained by the previously deposited layer. The maximum spacing between the layers, $l x$ (see 


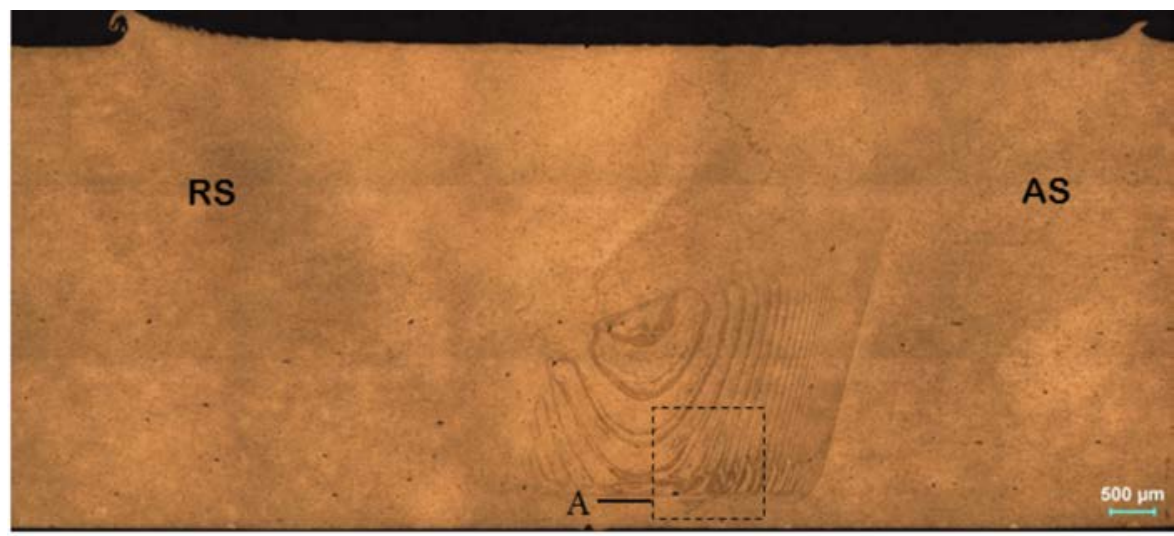

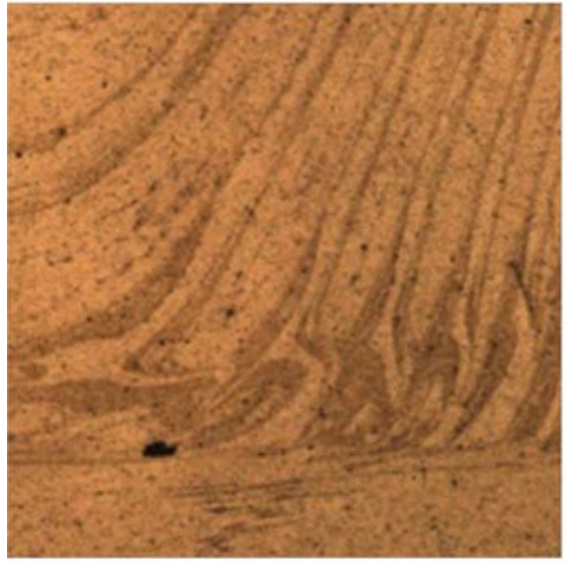

Detail A

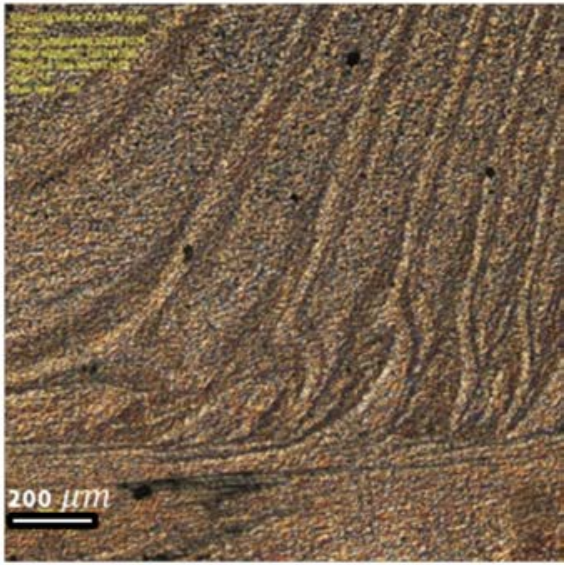

Detail A in DIC analysis

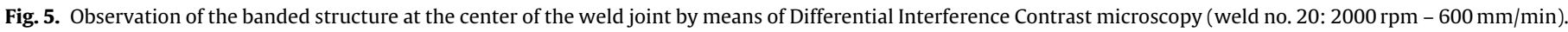

Fig. 7), is achieved when the tip of the tool is located at the center of the weld joint width. For the trigonal pin, the maximal value of $l x$ is equal to the distance between the identical bands defined by:

$l x=\frac{2 \pi V_{\text {feed }}}{k \omega}$

where $k$ depends on the geometry of the pin: $k$ equals 3 for the trigonal pin.

Furthermore, at the beginning of the layer deposition process, as shown in Fig. 7, this space is too thin for the material to be released. Therefore, a void is created in the retreating side of the weld (see Fig. 7).

\subsection{Effect of the velocities on the weld quality}

For a given tool geometry and materials to be joined, the material flow is governed by the welding speed and the rotational speed. The welds are of satisfactory quality if the banded structure is regular without any void defect. As these two characteristics depend on the material flow, the microstructure of the joint was investigated as a function of the welding speed and the rotational speed. In FSW, heat is generated by the friction as well as deformation heating. The heat increases with the rotational speed whereas it decreases with the feed speed. To avoid the lack of mixing, the rotational speed should be increased. However, a high feed speed is required for decreasing the process duration.

\subsubsection{Feed speed}

In the present investigation, the influence of feed velocity effect was studied for a rotational speed of $2000 \mathrm{rpm}$. Typical microstructures obtained under these processing conditions are shown in Fig. 8.

For low feed speeds (corresponding to small values of $l x$ ), Fig. 8(a) shows that the banded structures covers a small width of the weld with an irregular material flow. When the feed speed increases (corresponding to an increase of $l x$ ), the banded structure extends increasingly across the width of the weld and the bands become more and more regular as shown in Fig. 8(c)-(e). However, the feed speed of $600 \mathrm{~mm} / \mathrm{min}$ leads to a very regular banded structure but the zone of occurrence decreases as shown in Fig. 8(e). The feed speed is limited by the welding machine capabilities. This is the reason why the feed speed do not exceeds $600 \mathrm{~mm} / \mathrm{min}$ for a rotational speed of $2000 \mathrm{rpm}$ despite the potential interest to investigate higher feed speeds.

\subsubsection{Rotational speed}

When the rotational speed is low (corresponding to high values of $l x$ ), the banded structure is regular and well marked but only covers a small area of the weld width as shown in Fig. 9(a). When the rotational speed increases, the banded structure exhibits a regular periodicity and extends across the width of the weld (see Fig. 9(b)). For high rotational speeds, Fig. 9(c) shows that the zone corresponding to the banded structure decreases in the weld width and the thickness of the bands becomes irregular. Similar behavior is observed for an increase of the feed speed or a decrease of the rotational speed. Therefore, the evolution of the microstructure can be defined by means of the single parameter $l x$ which can be computed using only two process parameters: feed and rotational speeds. 


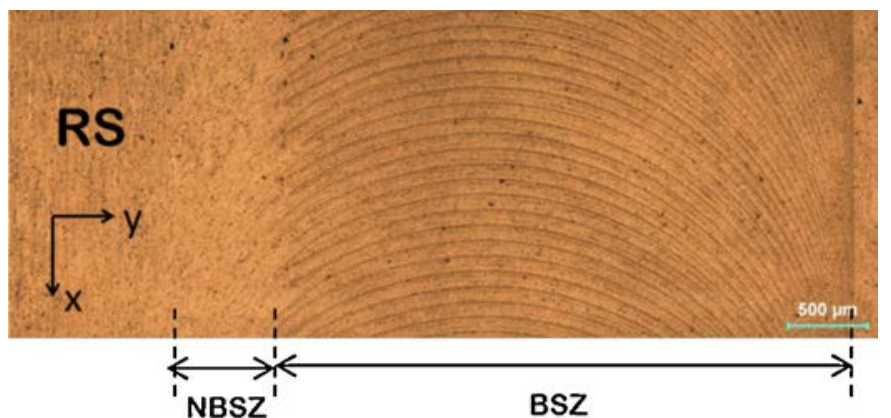

(a) Normal light microscopy

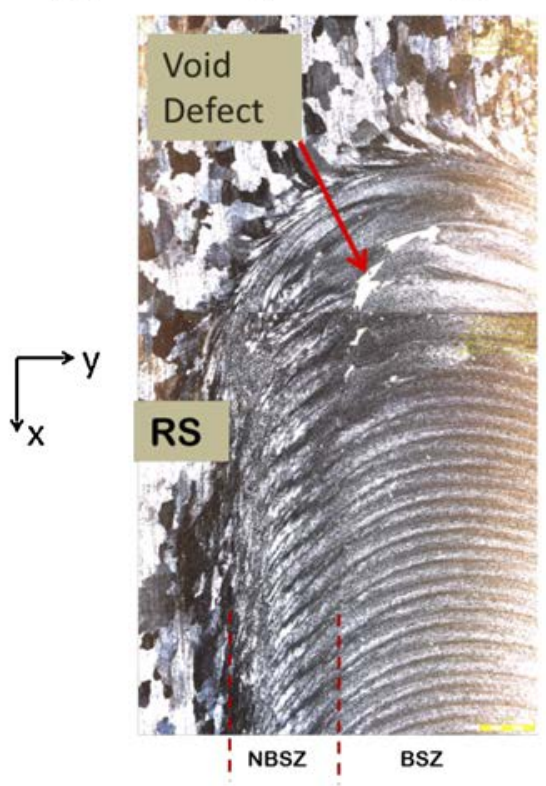

(b) Polarized light microscopy

Fig. 6. Optical observation at the beginning of the weld of the section $A-A$ in Fig. 4 (weld no. 20: $2000 \mathrm{rpm}-600 \mathrm{~mm} / \mathrm{min}$ ).

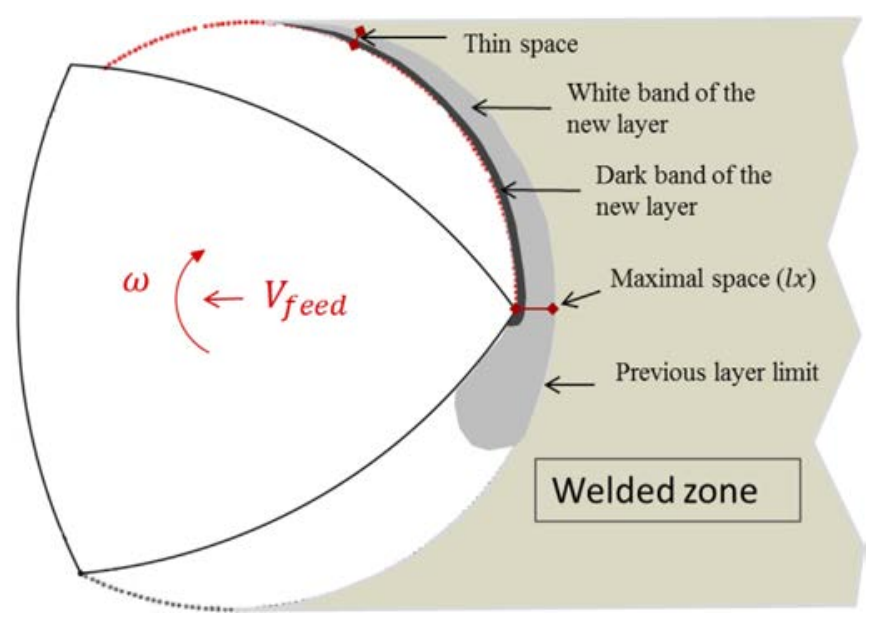

Fig. 7. Different zones across the weld.

\subsubsection{Discussion}

When $l x$ is small, i.e the distance between bands is small, it is difficult for the welded material to be deposited because the distance between the tool tip and the layer previously deposited is too small. Therefore, the new layer is not deposited across the entire weld width. A first part has to be deposited on the advancing side whereas the rest of the material is pushed by the tool (bluild-up) in its rotation as explained by Prangnell and Heason (2005). This phenomenon occurs several times thereby creating a block of material that detaches at the back of the pin by forming an irregular banded structure with a large band thickness. This sequence depends on the material flow that can be affected by the temperature. The blocks of material are composed of highly sheared material (corresponding to dark blocks) or less sheared (corresponding to light blocks). If $l x$ is high enough, material deposition occurs over the entire width of the stirring zone. The banded structure covers almost the weld width as shown in Fig. 8(e).

\section{Numerical investigation into the formation of the banded structure}

The numerical approach is of interest as it makes it possible to predict material flow inside the welding zone. Such information would very difficult to obtain experimentally. In this study, the focus is placed on the formation of the banded structure in the section $A-A$ defined in Fig. 4. Because this section is out of the vertical motion zone previously noticed in Fig. 4, the material flow is only driven by the circulation velocity around the pin. The kinematic of the material particles can be assumed to be bidimensional. In the following, the steps used for the development of the 2D numerical model for predicting the formation of the banded structure in the section $A-A$ (Fig. 4 ) is detailed.

\subsection{Numerical model setup}

\subsubsection{Coupled Eulerian-Lagrangian formulation}

The numerical FSW modeling process developed in this study is based on a Coupled Eulerian-Lagrangian (CEL) technique with an explicit time integration available in the computer code Abaqus ${ }^{\circledR}$ (2015). This approach allows plunging a Lagrangian rigid body such as a pin inside an Eulerian media where the base material flows. In a standard Lagrangian analysis, the motion is identical for the mesh and the material. Therefore, the boundary of the material coincides with the mesh boundary. For an Eulerian approach, the finite element mesh is fixed in space corresponding to a computational grid in which the material can flow. This mesh can be partially or completely empty of material. For the CEL technique, the boundary of the volume occupied by the material is described by a surface which cross the Eulerian media. The surface is tracked at each time step and it serves as geometrical support for the treatment of the contact between the material and the tool in the mixture theory provided by Benson (1997) for the Coulomb friction law. For the visualization, the computer code Abaqus ${ }^{\circledR}$ (2015) has not the ability to plot the surface used for the CEL computation that crosses elements. The visualization of the boundary is carried out by means of the EVF (Eulerian Void Fraction) field output based on nodal averaging values of the void fraction in each element of the mesh.

Fig. 10 shows an example of the void fraction field during the $2 \mathrm{D}$ rotation of the trigonal pin in section $A-A$. The CEL technique is only available in 3D in the computer code Abaqus ${ }^{\circledR}$ (2015). To implement the 2D simulation of the material flow in section $A-A$, the model is composed of a layer of 3D finite elements with no possible displacement in the out of plane direction. The mesh has a square shape of $15 \mathrm{~mm}$ side. Heat transfer is not computed by considering a constant temperature equal to $300^{\circ} \mathrm{C}$. The material 


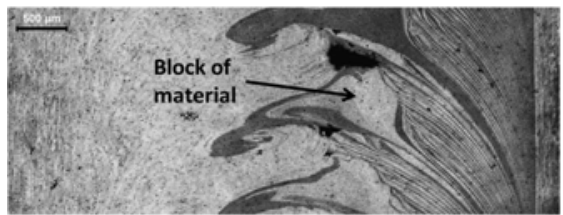

(a) $100 \mathrm{~mm} / \mathrm{min}$

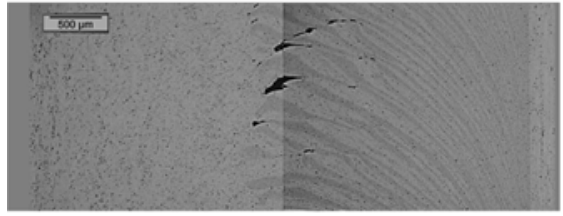

(b) $200 \mathrm{~mm} / \mathrm{min}$

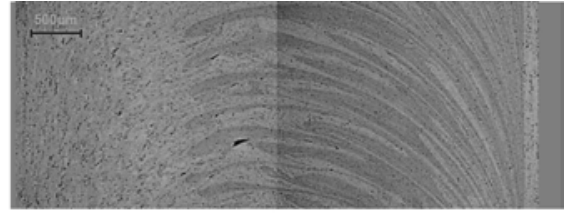

(c) $300 \mathrm{~mm} / \mathrm{min}$

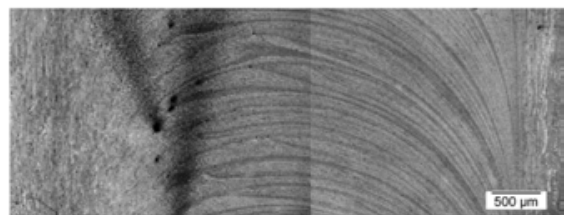

(d) $500 \mathrm{~mm} / \mathrm{min}$

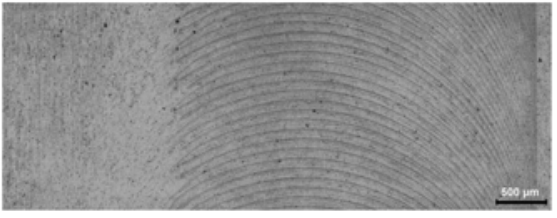

(e) $600 \mathrm{~mm} / \mathrm{min}$

Fig. 8. Microstructure observations at the center of the weld joint in the section $A-A$ (Fig. 4 ) for a rotational speed equal to 2000 rpm.

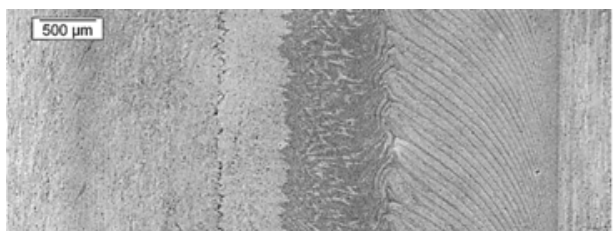

(a) $1000 \mathrm{rpm}$

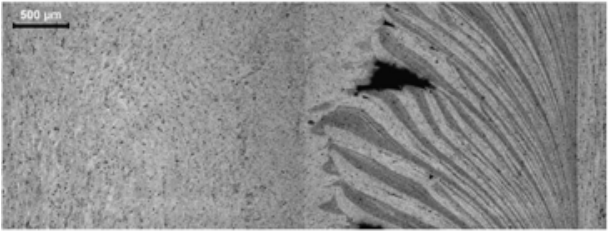

(c) $1750 \mathrm{rpm}$

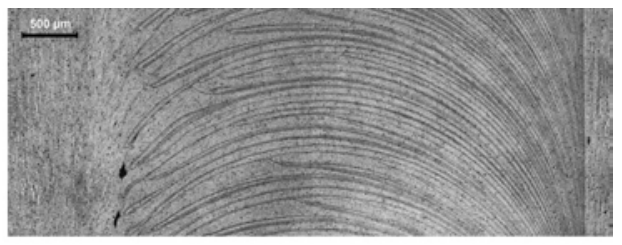

(b) $1500 \mathrm{rpm}$

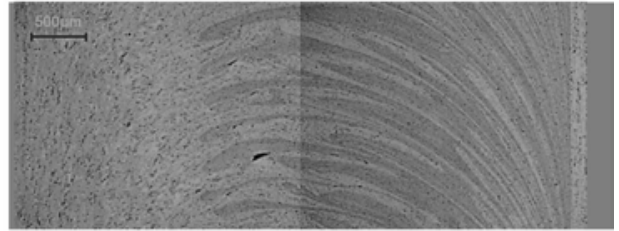

(d) $2000 \mathrm{rpm}$

Fig. 9. Microstructure of the joint at the center of the weld joint in the section $A-A$ (Fig. 4 ) for a feed speed of $300 \mathrm{~mm} / \mathrm{min}$.

is assumed to be initially motionless. Then, the material is forced to enter in the mesh with no possible transversal displacement on each side of the welding zone.

\subsubsection{Material behavior}

The material behavior is modeled by means of the Johnson-Cook material model for AA6061-T6 aluminum alloy because of the robustness of the parameters which have been used to simulate FSW by Lesuer et al. (2001), Soundararajan et al. (2005) and AlBadour et al. (2013):

$\sigma=\left(A+B\left(\varepsilon_{e q}^{p}\right)^{n}\right) \cdot\left(1+C \ln \left(\frac{\dot{\varepsilon}_{e q}^{p}}{\dot{\varepsilon}_{0}}\right)\right) \cdot\left(1-\hat{T}^{m}\right)$

where $A, B, n, m, C$ are material parameters given in Table 1. $\varepsilon_{e q}^{p}$ and $\dot{\varepsilon}_{e q}^{p}$ denote respectively the equivalent plastic strain and the equivalent plastic strain rate. $\hat{T}$ is a non-dimensional temperature defined as:

$$
\hat{T}= \begin{cases}0 & \text { if } T \leq T_{\text {tran }} \\ \frac{T-T_{\text {tran }}}{T_{\text {melt }}-T_{\text {tran }}} & \text { if } T_{\text {tran }}<T<T_{\text {melt }} \\ 1 & \text { if } T \geq T_{\text {melt }}\end{cases}
$$

where $T_{\text {melt }}, T_{\text {tran }}$ and $T$ denote respectively the melting, the transition and the material temperatures (taken equal to $300^{\circ} \mathrm{C}$ ).

\subsubsection{Numerical robustness}

The mesh refinement is defined by the lengths of the edges of the finite elements which are denoted by $h$. In this work, $h$ depends on the distance between the bands of the microstructure to be simulated. For the configuration 20 (see Fig. 1), the distance between 
Table 1

Johnson-Cook parameters.

\begin{tabular}{|c|c|c|c|c|c|c|}
\hline$A(\mathrm{MPa})$ & $B(\mathrm{MPa})$ & $n$ & $m$ & $C$ & $T_{\text {melt }}\left({ }^{\circ} \mathrm{C}\right)$ & $T_{\text {tran }}\left({ }^{\circ} \mathrm{C}\right)$ \\
\hline 324 & 114 & 0.42 & 1.34 & 0.002 & 583 & 24 \\
\hline
\end{tabular}

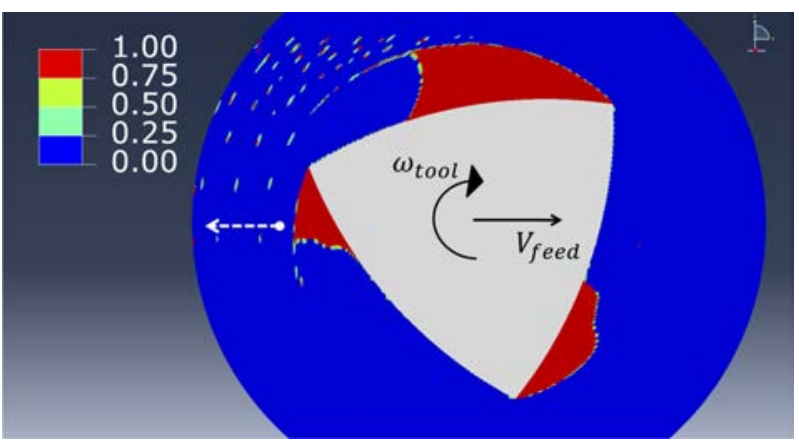

Fig. 10. Distribution of the void fraction around the trigonal pin during welding.

bands $l x$ equals $0.1 \mathrm{~mm}$. Therefore, the mesh size must be smaller. To avoid a major computation cost, a numerical feed speed equal to $2000 \mathrm{~mm} / \mathrm{min}$ was used leading to a value of $l x$ of about $0.33 \mathrm{~mm}$. The simulations were performed during a physical time equal to $0.6 \mathrm{~s}$ which corresponds to 20 rotations for a rotational velocity of $2000 \mathrm{rpm}$. With this approach, the periodic state corresponding to the real welding stage was achieved.

To test the robustness of the numerical 2D modeling process, the influence of the mesh size $h$ was also investigated by taking $h$ equal to $24 \mu \mathrm{m}, 12 \mu \mathrm{m}, 6 \mu \mathrm{m}$ and $3 \mu \mathrm{m}$ as described in Table 2 . All the above computations were carried out by considering a Coulomb

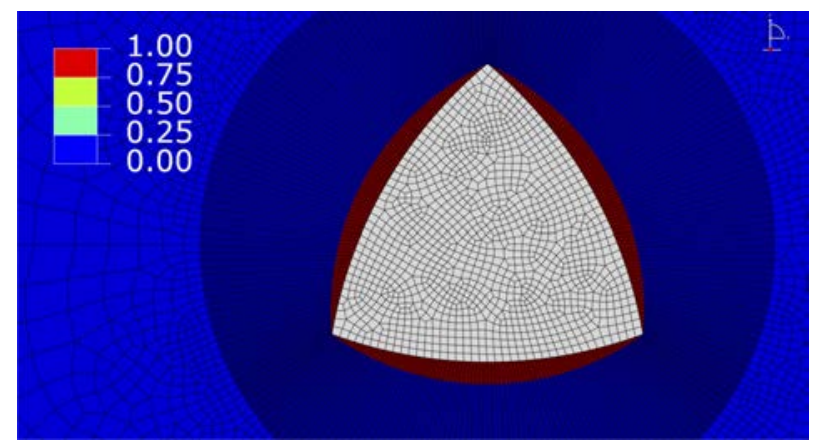

Fig. 11. Eulerian mesh $(h=12 \mu \mathrm{m})$ and initial distribution of the void fraction.

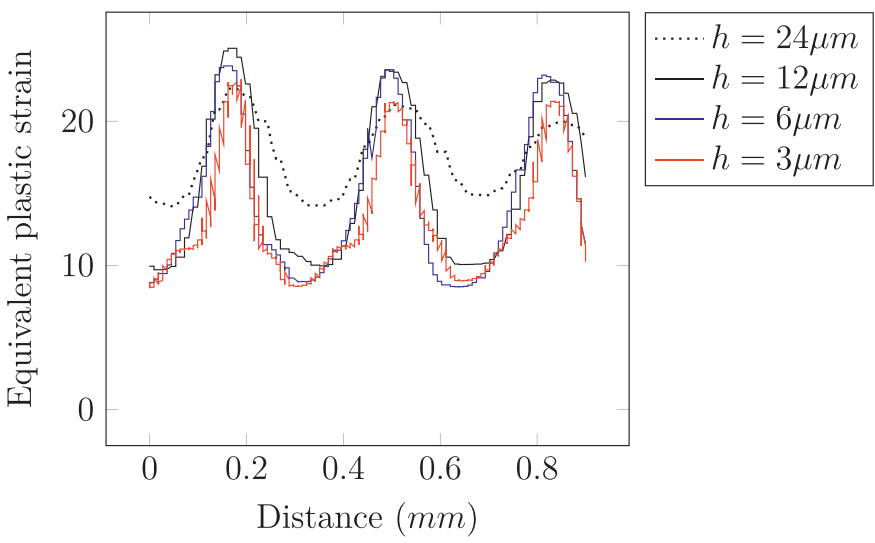

Fig. 12. Equivalent plastic strain $\varepsilon_{e q}^{p}$ along the white arrow (see Fig. 10).

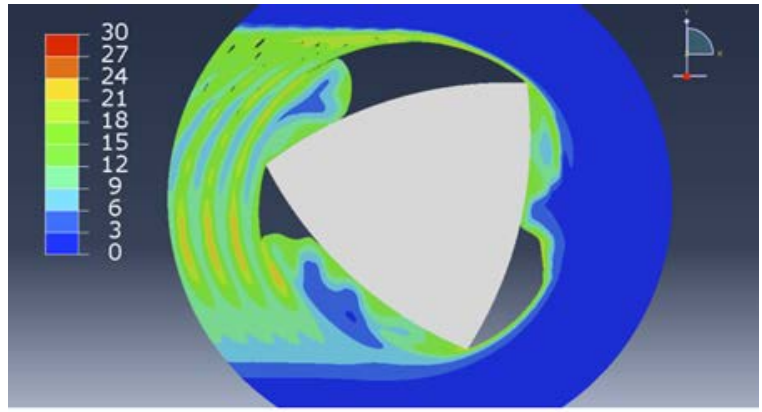

(a) $200^{\circ} \mathrm{C}$

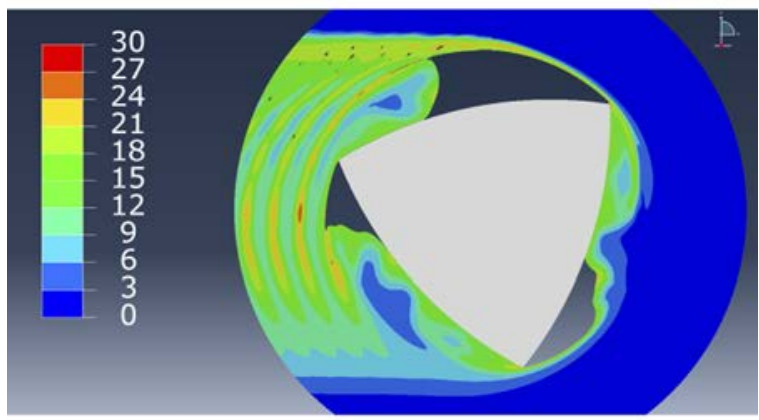

(b) $300^{\circ} \mathrm{C}$

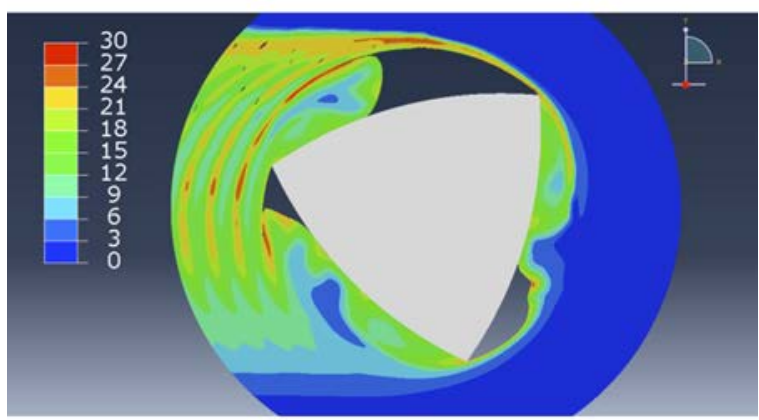

(c) $400^{\circ} \mathrm{C}$

Fig. 13. Distribution of the equivalent plastic strain $\varepsilon_{e q}^{p}$ for different temperatures $(h=12 \mu \mathrm{m})$.

coefficient equal to 0.3 for modeling the contact between the pin and the material. As an illustrative example, Fig. 11 shows the mesh for $h=12 \mu \mathrm{m}$. For all simulations described in Table 2, the Eulerian mesh is initially empty of material at the tool location and between the pin and the material, as shown in red color in Fig. 11. The cavities between the tool and the material were introduced in the model following the observations of Chen and Cui (2008) in the case of cylindrical pin.

The distributions of plastic strain for the simulations of Table 2 are plotted in Fig. 12 along the white line crossing the banded structure in the center of the weld (see Fig. 10). The comparison shows that the $h=12 \mu \mathrm{m}$ finite element mesh appears to be the 
Table 2

Description of the numerical simulations for a welding time of $0.6 \mathrm{~s}$, a trigonal pin and a Coulomb's coefficient equal to 0.3 .

\begin{tabular}{|c|c|c|c|c|}
\hline Element size (h) & $24 \mu \mathrm{m}$ & $12 \mu \mathrm{m}$ & $6 \mu \mathrm{m}$ & $3 \mu \mathrm{m}$ \\
\hline Number of nodes & 22,435 & 82,440 & 166,048 & 291,590 \\
\hline CPU time & $4 \mathrm{~h} 18 \mathrm{~min}$ & $29 \mathrm{~h} 35 \mathrm{~min}$ & 94 h 5 min & 351 h $34 \mathrm{~min}$ \\
\hline
\end{tabular}

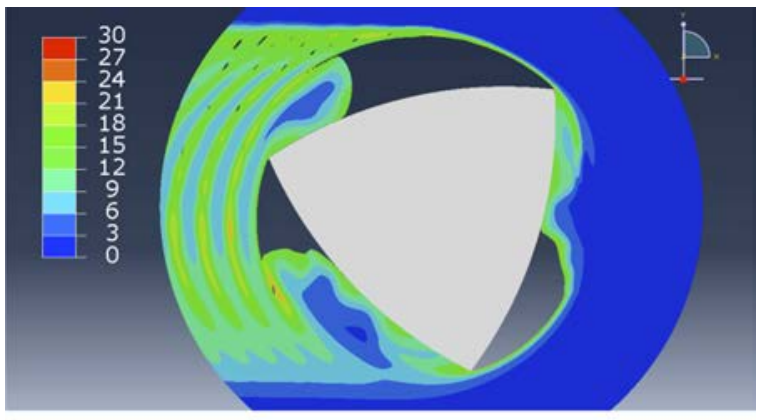

(a) with a circular initial void

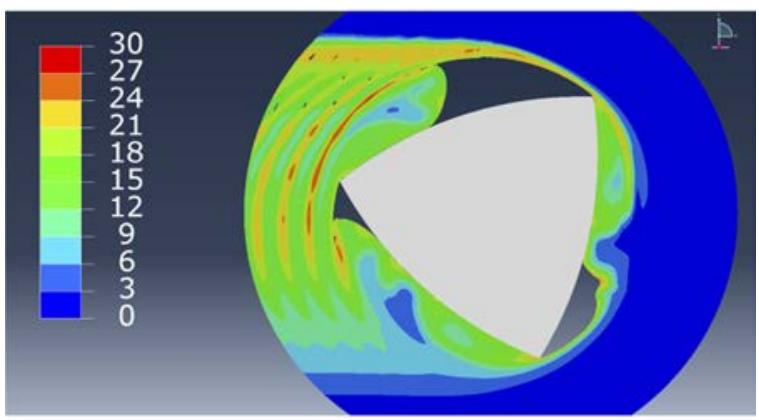

(b) without initial void

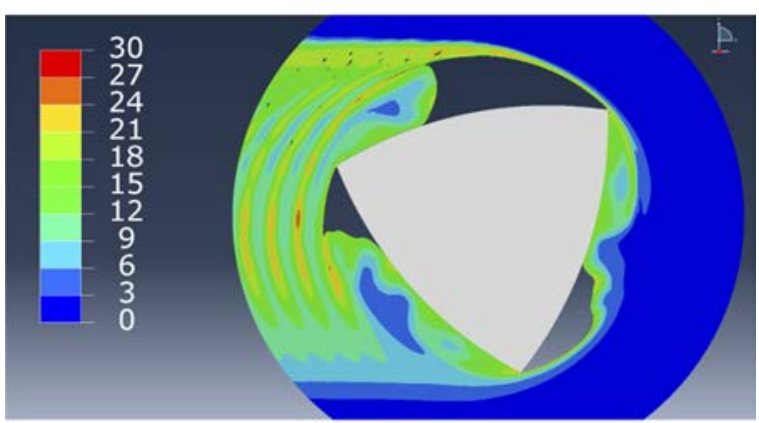

\section{(c) with the initial void of Fig. 11}

Fig. 14. Distribution of the equivalent plastic strain $\varepsilon_{e q}^{p}(h=12 \mu \mathrm{m})$.

most efficient one. Indeed, the refined discretizations (i.e. lower $h$ value) do not seem to be significantly more accurate. The mesh size $h$ will be taken equal to $12 \mu \mathrm{m}$ for the rest of the numerical investigation dedicated to the study of the formation of the banded structure. In order to investigate the possible influence of the presence initial cavities between the tool and the base material on the simulated periodic state of the welding stage, a simulation test was performed without considering initial cavities. Figs. 13 and 14 show that the plastic strain distribution at the back of the pin does not significantly depend on the temperature and the initial state because the cavities appear even when they are not initially considered.

\subsection{Simulation of the banded structure}

As discussed by Tongne et al. (2015), a relation can be established between the maximal strain rate values $\dot{\varepsilon}_{e q_{\max }}^{p}$ and the occurrence of the banded structure. Figs. 15 and 16 show respectively the distributions of $\dot{\varepsilon}_{e q_{\max }}^{p}$ and $\varepsilon_{e q}^{p}$ for different values of the Coulomb coefficient denoted $f$ which is taken equal to 0 (slip condition), 0.3 and 0.6. For the maximal equivalent strain rate, there are no significant differences between the three cases which cover realistic values of $f$. For each case, the banded structure appears at the back of the pin by an alternating pattern of high and low values of the maximal equivalent plastic strain rate. Fig. 16 shows that the friction condition has an effect on the morphology of the banded structure, since the BSZ is wider at low friction coefficient. The distribution of the maximal equivalent plastic strain rate $\dot{\varepsilon}_{e q_{\max }}^{p}$ across the banded structure is plotted in Fig. 17. The variation of the Coulomb coefficient does not significantly affect the evolution of $\dot{\varepsilon}_{e q_{\max }}^{p}$ but only the numerical maximal values which are lower for the highest value of $f$. This sensitivity of the material history according to $f$ is less remarkable with regard to the equivalent plastic strain as shown in Figs. 16 and 18.

As shown in Figs. 15 and 16, the banded structures are located on the advancing side of the weld, as obtained in the experimental work. In Fig. 19(a), the face of the pin denoted $s 1$, drives the welded material by pushing it near the tip $t 1$. The motion of the tip induces a high elongation of the boundary, denoted $b 1$, which can be observed by comparing Fig. 19(a) and (b). At the same time, the face, denoted $s 2$, digs the material at the front of the pin, in order to drive it in its movement while more or less deforming the boundary $b 1$. At the back of the pin, as the material is being released, the border, denoted $b 1$, is affected on the retreating side where there is a transition between the digging phenomenon and the material deposition.

\subsection{Numerical simulation of the material interface evolution}

To understand the material mixing and the formation mechanism of the material interface in section $A-A$, a state variable was defined in the numerical simulations. At the initial step, it is taken equal to 1 at nodes of the mesh belonging to a band width of about $20 \mu \mathrm{m}$ as plotted on the right side of Fig. 20 and 0 everywhere else. Fig. 20 shows the material interface obtained with the refined mesh $(h=3 \mu \mathrm{m})$. The shape of the interface describes a microstructure composed of alternating layers of material. This results is in agreement with the experimental observations of Xu and Deng (2008) who reported that the material interface is often dragged into the banded structures and exhibit more or less complex shapes. Similar observations were also reported by Gibson et al. (2014) and Robe et al. (2015). Therefore, the banded structure is highly related to the mixing of materials across the width of the weld.

To visualize the material mixing, the state variable was initially taken equal to 0 or 1 depending if the nodes of the mesh correspond to the material that comes from the left or the right side of the joint. In this case, the material interface can be identified in the multicolor zone located between the red and blue sides in Fig. 21. Referring to standard levelset techniques, the thickness of the interface is approximately equal to the size of the finite elements. It can be seen that the joint is made of bands, located at the back of the tool, composed of alternating material originating from each side. Each 


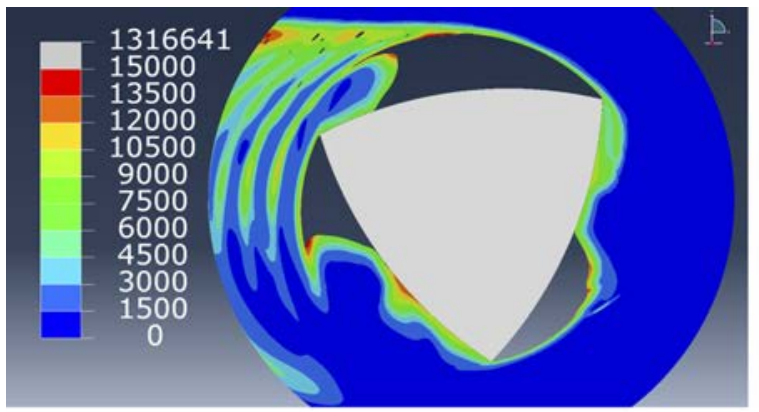

(a) $f=0$

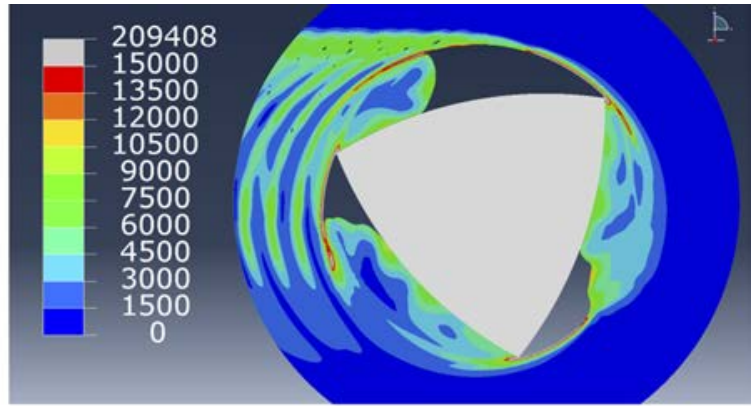

(b) $f=0.3$

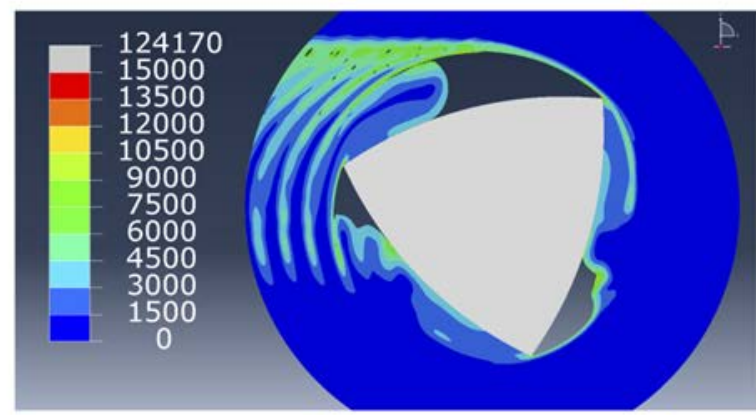

(c) $f=0.6$

Fig. 15. Distribution of the maximal equivalent plastic strain rate $\dot{\varepsilon}_{e q_{\max }}^{p}\left(\mathrm{~s}^{-1}\right)$ for different values of the Coulomb coefficient $f(h=12 \mu \mathrm{m})$.

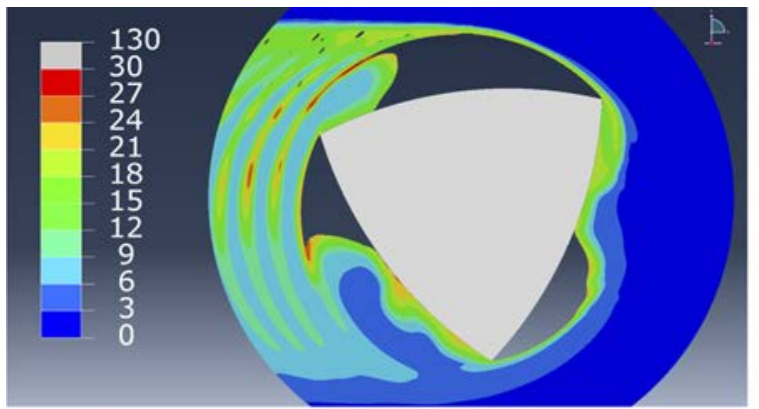

(a) $f=0$

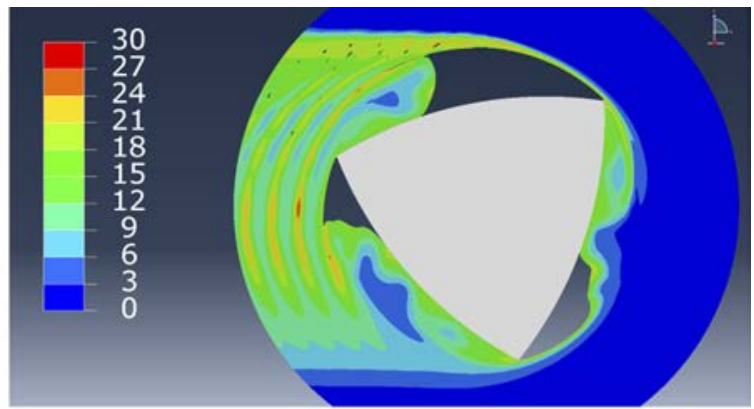

(b) $f=0.3$

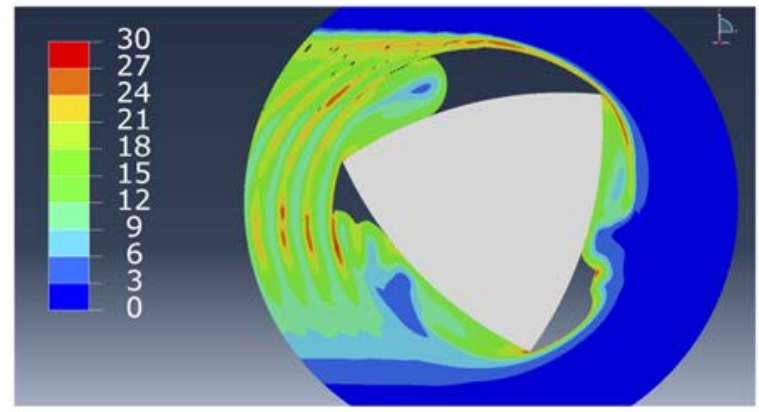

(c) $f=0.6$

Fig. 16. Distribution of the equivalent plastic strain $\varepsilon_{e q}^{p}$ for different values of the Coulomb coefficient $f(h=12 \mu \mathrm{m})$. 


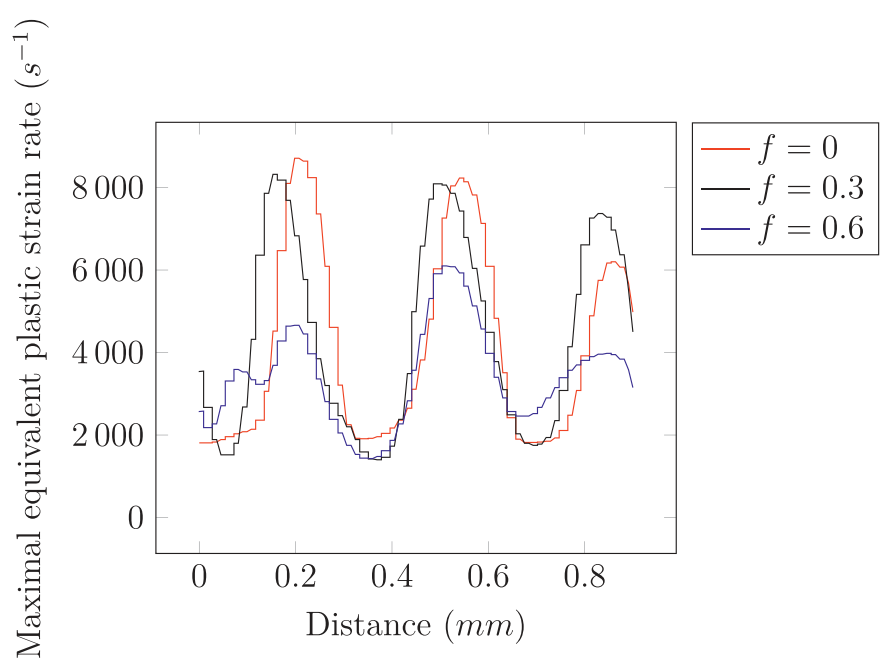

Fig. 17. Maximal equivalent plastic strain rate along the white arrow (see Fig. 10).

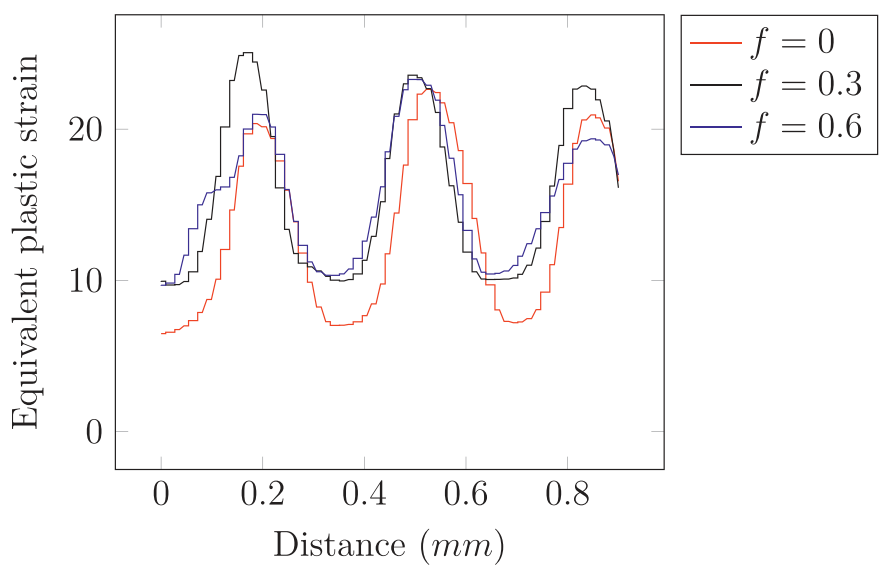

Fig. 18. Equivalent plastic strain along the white arrow (see Fig. 10).

layer is made of materials coming from both sides. The numerical banded structure is located on the advancing side regardless of the value of the Coulomb coefficient. On the retreating side, it can be seen that the weld does not exhibit banded structure as for the distribution of maximal strain rate. This agrees with the experimental observation: the zone located in the retreating side called NBSZ

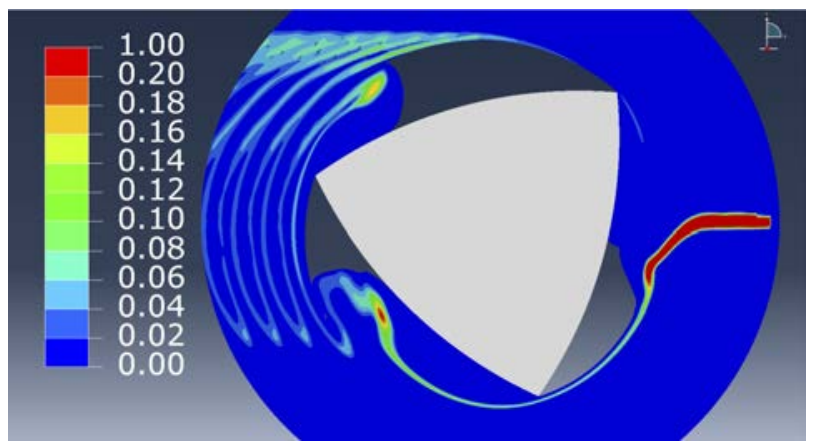

Fig. 20. Computed material interface for $f=0.3$ and $h=3 \mu \mathrm{m}$ in the section $A-A$ (see Fig. 4).

is composed of material which remains attached to the unmixed material. Moreover, the material interface gradually shifts to the advancing side as the Coulomb coefficient increases and so does the width of the NBSZ observed in Fig. 6(a).

\subsection{Perspectives for modeling of void defects}

The experimental investigation revealed that the banded structure was observed in the plane of the welded sheets. Using numerical modeling, the formation mechanism of the banded structure as well as the evolution of the material interface was discussed and simulated using the finite element method. Despite of the regular banded structure, a void defect can appear at the interface between the NBSZ and the BSZ as shown in Fig. 22. In this case, the defect has not been generated by a lack of material flow because it is not located on the advancing side close to the zone of highest plastic strain (see Fig. 16) as mentioned by Al-Badour et al. (2013). In Fig. 22, the void is the result of the fracture of the base material initiated in the NBSZ. For predicting such void defects, the numerical modeling needs to be improved. The material initially located on the retreating side seems to be driven into the banded structure while being separated from the base material (see Fig. 22). This phenomenon of separation of the material requires the development of a damage model taking into account the mechanical and thermal loads undergone by the material under the tool. This approach is necessary to simulate the formation mechanism of void defects and to study the impact of the welding parameters.

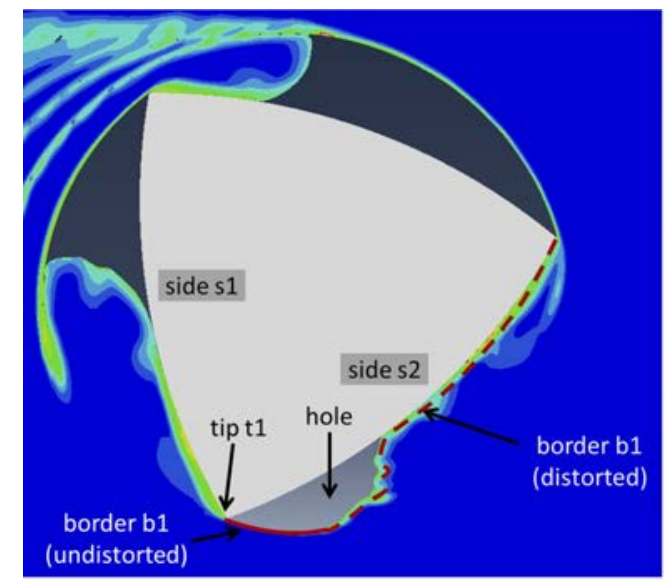

(a) in front of the pin

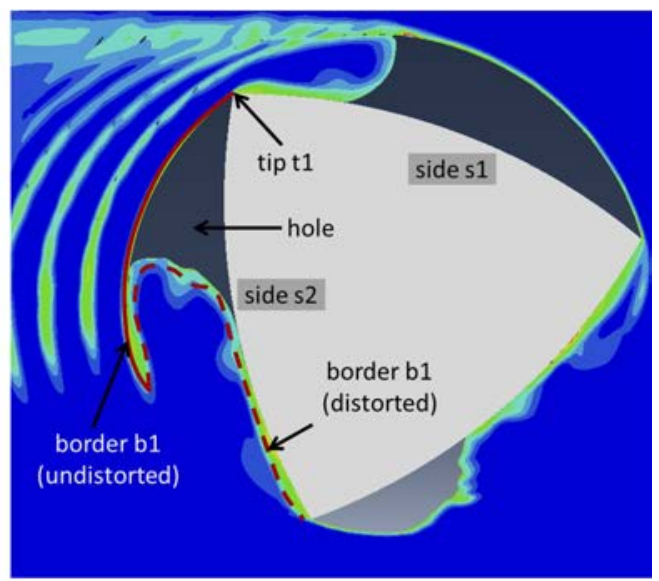

(b) at the back of the pin

Fig. 19. The welded material surface evolution around the pin. 


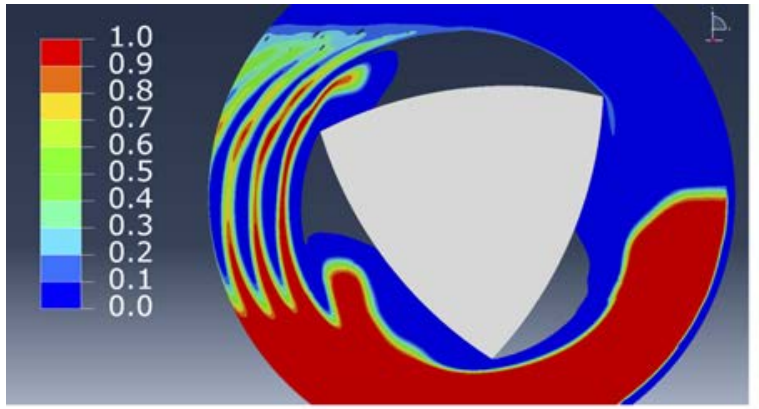

(a) $f=0$

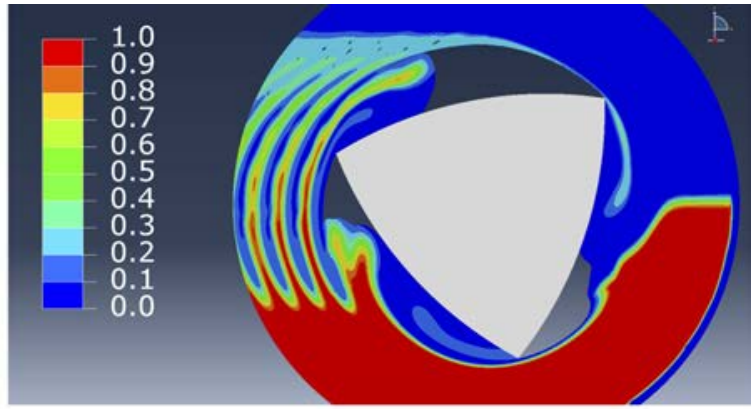

(b) $f=0.3$

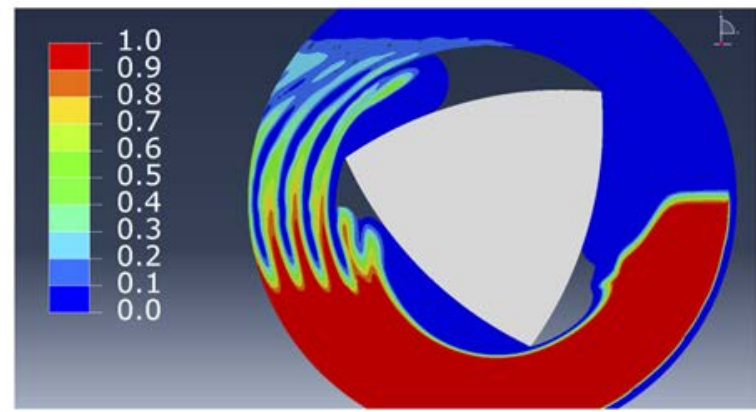

(c) $f=0.6$

Fig. 21. Mixing of the material coming from advancing and retreating sides for different values of the Coulomb coefficient $f(h=12 \mu \mathrm{m})$.

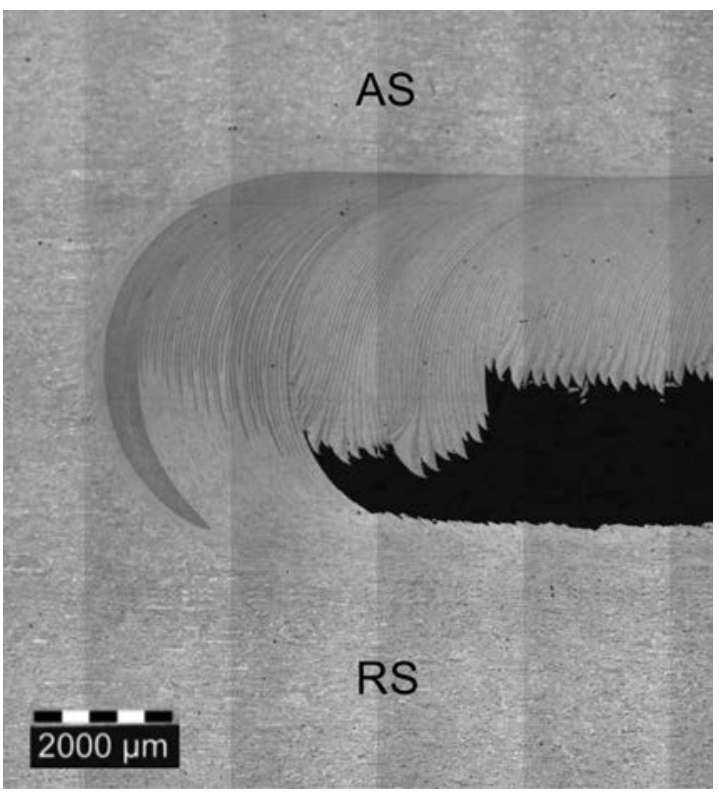

Fig. 22. Microstructure observation in the section $A-A$ for the weld no. 21 in Fig. 1.

\section{Conclusions}

The aim of this paper was to study material during FSW of AA6082-T6 using a trigonal pin by simulation and experimental validation. A 2D numerical modeling method has been developed on the basis of a coupled Eulerian-Lagrangian (CEL) approach for simulating the formation mechanism of a regular banded structure. The following main conclusions can be drawn from the present work:
1. Optical observations in the plane of the sheets to be welded show that the welding velocity needs to be high enough for a trigonal pin to obtain a regular banded structure.

2. The model confirms that contrast difference between bands of microstructure can be correlated to the maximal equivalent plastic strain rate.

3. The model attests that bands of microstructure across the width of the weld are composed of alternating layers of material coming from each side of the joint.

4. By using the Coulomb coefficient, the numerical model shows that the banded structure mainly depends on the trigonal shape of the pin, not on the friction condition.

\section{References}

Abaqus $^{\circledR}, 2015$. User's Manual. Abaqus Inc

Al-Badour, F., Merah, N., Shuaib, A., Bazoune, A., 2013. Coupled Eulerian Lagrangian finite element modeling of friction stir welding processes. J. Mater. Process. Technol. 213 (8), 1433-1439 http://linkinghub.elsevier.com/retrieve/pii/ S0924013613000745.

Assidi, M., Fourment, L., Guerdoux, S., Nelson, T., 2010. Friction model for friction stir welding process simulation: calibrations from welding experiments. Int. J. Mach. Tools Manuf. 50 (2), 143-155, http://dx.doi.org/10.1016/j.ijmachtools. 2009.11.008 http://www.sciencedirect.com/science/article/pii/ S0890695509002363.

Bastier, A., Maitournam, M.H., Dang Van, K., Roger, F., 2006. Steady state thermomechanical modelling of friction stir welding. Sci. Technol. Weld. Join. 11 (3), 278-288, http://dx.doi.org/10.1179/174329306X102093.

Benson, D.J., 1997. A mixture theory for contact in multi-material Eulerian formulations. Comput. Methods Appl. Mech. Eng. 140, 59-86.

Chen, Z., Cui, S., 2008. On the forming mechanism of banded structures in aluminium alloy friction stir welds. Scr. Mater. 58 (5), 417-420 http:// linkinghub.elsevier.com/retrieve/pii/S135964620700752X.

Colegrove, P., Shercliff, H., 2004. Development of Trivex friction stir welding tool. Part 2 - Three-dimensional flow modelling. Sci. Technol. Weld. Join. 9 (4), 352-361, http://dx.doi.org/10.1179/136217104225021661.

Colligan, K., 1999. Material flow behaviour during friction welding of aluminum. Weld. J. 78 (7), 229s-237s http://cat.inist.fr/ ?aModele=afficheN\&cpsidt $=1877048$. 
Cui, G., Ma, Z., Li, S., 2008. Periodical plastic flow pattern in friction stir processed Al-Mg alloy. Scr. Mater. 58 (12), 1082-1085 http://linkinghub.elsevier.com/ retrieve/pii/S1359646208001218.

Dialami, N., Chiumenti, M., Cervera, M., de Saracibar, C.A., 2013. An apropos kinematic framework for the numerical modeling of friction stir welding. Comput. Struct. 117, 48-57.

Ericsson, M., Sandström, R., 2003. Influence of welding speed on the fatigue of friction stir welds, and comparison with MIG and TIG. Int. J. Fatigue 25 (12), 1379-1387 http://linkinghub.elsevier.com/retrieve/pii/S0142112303000598.

Feulvarch, E., Roux, J.-C., Bergheau, J.-M., 2012. A simple and robust moving mesh technique for the finite element simulation of Friction Stir Welding. J. Comput. Appl. Math., 1-9 http://www.sciencedirect.com/science/article/pii/ S0377042712003032.

Gibson, B., Lammlein, D., Prater, T., Longhurst, W., Cox, C., Ballun, M., Dharmaraj, K., Cook, G., Strauss, A., 2014. Friction stir welding: process, automation, and control. J. Manuf. Process. 16 (1), 56-73 http://www.sciencedirect.com/ science/article/pii/S1526612513000601.

Giraud, L., Robe, H., Claudin, C., Desrayaud, C., Bocher, P., Feulvarch, E., 2016. Investigation into the dissimilar friction stir welding of AA7020-T651 and AA6060-T6. J. Mater. Process. Technol. 235, 220-230.

Gratecap, F., Girard, M., Marya, S., Racineux, G., 2011. Exploring material flow in friction stir welding: tool eccentricity and formation of banded structures. Int J. Mater. Form. 5 (2), 99-107, http://dx.doi.org/10.1007/s12289-010-1008-5.

Jacquin, D., De Meester, B., Simar, A., Deloison, D., Montheillet, F., Desrayaud, C., 2011. A simple Eulerian thermomechanical modeling of friction stir welding. J. Mater. Process. Technol. 211 (1), 57-65 http://www.sciencedirect.com/ science/article/pii/S092401361000258X.

Jene, T., Dobmann, G., Wagner, G., Eifler, D., 2006. Oxide Fragments in Friction Stir Welds, vol. 5454., pp. 3-8.

Krishnan, K., 2002. On the formation of onion rings in friction stir welds. Mater. Sci. Eng. A 327 (2), 246-251 http://www.sciencedirect.com/science/article/pii/ S0921509301014745.

Kumar, K., Kailas, S., 2008. The role of friction stir welding tool on material flow and weld formation. Mater. Sci. Eng. A 485 (1-2), 367-374 http://linkinghub. elsevier.com/retrieve/pii/S0921509307015419.

Lesuer, D., Kay, G., Leblanc, M., 2001. Modeling Large-Strain, High-Rate Deformation in Metals. Report No. UCRL-JC-134118. Lawrence Livermore National Laboratory, Livermore, Canada.

Liechty, B., Webb, B., 2007. The use of plasticine as an analog to explore material flow in friction stir welding. J. Mater. Process. Technol. 184 (1-3), 240-250, http://dx.doi.org/10.1016/j.jmatprotec.2006.10.049 http://linkinghub.elsevier. com/retrieve/pii/S092401360600940X.

Lorrain, O., Zahrouni, H., Hadrouz, M.E., 2009. A contribution to a critical review of friction stir welding numerical simulation. Mech. Mater. Struct. 4 (February).

Malik, V., Sanjeev, N., Hebbar, H.S., Kailas, S.V., 2014. Time efficient simulations of plunge and dwell phase of FSW and its significance in FSSW. Procedia Mater.
Sci. 5, 630-639 http://linkinghub.elsevier.com/retrieve/pii/ S2211812814006749.

Prangnell, P., Heason, C., 2005. Grain structure formation during friction stir welding observed by the 'stop action technique'. Acta Mater. 53 (11), 3179-3192 http://linkinghub.elsevier.com/retrieve/pii/ S1359645405001722.

Rajakumar, S., Muralidharan, C., Balasubramanian, V., 2011. Influence of friction stir welding process and tool parameters on strength properties of AA7075-T6 aluminium alloy joints. Mater. Des. 32 (2), 535-549 http://linkinghub.elsevier. com/retrieve/pii/S0261306910005005.

Robe, H., Zedan, Y., Chen, J., Monajatib, H., Feulvarch, E., Bocher, P., 2015. Microstructural and mechanical characterization of a dissimilar friction stir welded butt joint made of AA2024-T3 and AA2198-T3. Mater. Charact. 110, 242-251.

Schmidt, H., Hattel, J., 2005. A local model for the thermomechanical conditions in friction stir welding. Model. Simul. Mater. Sci. Eng. 13 (1), 77-93 http://stacks. iop.org/0965-0393/13/i=1/a=006.

Soundararajan, V., Zekovic, S., Kovacevic, R., 2005. Thermo-mechanical model with adaptive boundary conditions for friction stir welding of Al 6061. Int. J. Mach. Tools Manuf. 45, 1577-1587.

Taban, E., Kaluc, E., 2007. Comparison between microstructure characteristics and joint performance of 5086-H32 aluminium alloy welded by MIG, TIG and friction stir welding processes. Kovove Mater. 90 (262), 11-14.

Tartakovsky, A., Grant, G., Sun, X., Khaleel, M., 2006. Modeling of Friction Stir Welding (FSW) Process with Smooth Particle Hydrodynamics (SPH). http:// papers.sae.org/2006-01-1394/.

Timesli, A., Braikat, B., Zahrouni, H., Moufki, A., Lahmam, H., 2012. Toward friction stir welding simulation using moving least square technique. In: 2nd International Conference on Friction Stir Welding and Processing FSWP'2012, pp. 119-121.

Tongne, A., Jahazi, M., Feulvarch, E., Desrayaud, C., 2015. Banded structures in friction stir welded Al alloys. J. Mater. Process. Technol. http://www. sciencedirect.com/science/article/pii/S0924013615000631.

Tutum, C.C., Hattel, J.H., 2011. Numerical optimisation of friction stir welding: review of future challenges. Sci. Technol. Weld. Join. 16 (4), 318-324, http://dx. doi.org/10.1179/1362171811Y.0000000011.

$\mathrm{Xu}, \mathrm{S}$., Deng, X., 2008. A study of texture patterns in friction stir welds. Acta Mater. 56 (6), 1326-1341 http://www.sciencedirect.com/science/article/pii/ S1359645407007938.

Yoshikawa, G., Miyasaka, F., Hirata, Y., Katayama, Y., Fuse, T., 2012. Development of numerical simulation model for FSW employing particle method. Sci. Technol. Weld. Join. 17 (4), 255-263, http://dx.doi.org/10.1179/1362171811Y. 0000000099.

Zhou, C., Yang, X., Luan, G., 2006. Effect of oxide array on the fatigue property of friction stir welds. Scr. Mater. 54 (8), 1515-1520 http://www.sciencedirect. com/science/article/pii/S1359646206000066. 